DR. ARTUR PALASZ (Orcid ID : 0000-0002-2632-1211)

Article type : Review Article

\title{
Molecular neurochemistry of the lanthanides
}

Corresponding author mail-id:- apalasz@ sum.edu.pl

Artur Pałasz ${ }^{1}$, Yolanda Segovia ${ }^{2}$, Rafał Skowronek ${ }^{3}$, John J.Worthington ${ }^{4}$

${ }^{1}$ Department of Histology, School of Medicine in Katowice, Medical University of Silesia, Medyków Street 18, 40-752, Katowice, Poland

${ }^{2}$ Department of Biotechnology, University of Alicante, Apartado 99, 03080, Alicante, Spain

${ }^{3}$ Department of Forensic Medicine and Forensic Toxicology, School of Medicine in Katowice, Medical University of Silesia, Medyków Street 18, 40-752, Katowice, Poland

${ }^{4}$ Division of Biomedical and Life Sciences, Faculty of Health and Medicine, Lancaster University, Lancaster, LA1 4YQ, UK

Abstract

Lanthanides, once termed rare-earth elements, are not as sparce in the environment as their traditional name suggests. Mean litospheric concentrations are in fact comparable to the physiologically fundamental elements such as iodine, cobalt and selenium. Recent advances in medical technology have resulted in accumulation of lanthanides presenting potential exposure to both our central and peripheral nervous systems. Extensive and detailed studies on these peculiar active metals in the context of their influence on neural functions are therefore urgently required. Almost all neurochemical effects of trivalent lanthanide ions appear to result from the similarity of their radii to the key signaling ion calcium. Lanthanides, especially $\mathrm{La}^{3+}$ and $\mathrm{Gd}^{3+}$ block different types of calcium, potassium and sodium channels in human and animal neurons, regulate neurotransmitter turnover and release, as well as synaptic activity. Lanthanides also act as modulators of several ionotropic receptors, e.g. GABA, NMDA, and kainate and can also affect numerous signaling mechanisms including NF- $\mathrm{B}$ B and apoptotic-related endoplasmic reticulum IRE1-XBP1, PERK and ATF6 pathways. Several lanthanide ions may cause oxidative neuronal injuries and functional impairment by promoting reactive oxygen species (ROS) production. However, cerium and yttrium oxides have some unique and promising neuroprotective properties, being able to decrease free radical cell injury and even alleviate motor impairment and cognitive function in animal models of multiple sclerosis and mild traumatic brain damage respectively. In conclusion, lanthanides affect various neurophysiological processes, altering a large spectrum of brain functions. Thus, a deeper understanding of their potential mechanistic roles during disease and as therapeutic agents requires urgent elucidation.

This article has been accepted for publication and undergone full peer review but has not been through the copyediting, typesetting, pagination and proofreading process, which may lead to differences between this version and the Version of Record. Please cite this article as doi: 10.1002/syn.22119

This article is protected by copyright. All rights reserved. 
Key words: lanthanides, synaptic transmission, oxidative injury, neuroprotection

1. Introduction

Lanthanides, often named "rare earth elements" (REEs) are lustrous, silverywhite or goldish, relatively soft and plastic metals, whose atomic numbers range from 57 to 71 (Fig 1.). For almost a century lanthanides were considered intriguing laboratory curiosities. Sir William Crookes, an outstanding English chemist described them in 1887: "...These elements perplex us in our researches, baffle us in our speculations and haunt us in our very dreams. They stretch like an unknown sea before us - mocking, mystifying and murmuring strange revelations and possibilities..." Because of their high chemical reactivity, lanthanides never exist in nature as pure elements, but only as sparsely distributed compounds that form rare minerals. Scandium and yttrium, also classified as REEs are not formal members of the lanthanide family, however due to their considerable chemical analogy to this group, they are usually described jointly. Importantly, the ionic radii of $\mathrm{La}^{3+}, \mathrm{Ce}^{3+}$, $\mathrm{Pr}^{3+}, \mathrm{Nd}^{3+}$ and $\mathrm{Gd}^{3+}$ are comparable to that of $\mathrm{Ca}^{2+}$, an ion that plays a crucial regulatory role in several cell functions (Pałasz and Czekaj 2000). This particular structural similarity determines the physiological and toxicological effects of soluble lanthanide salts (Xu et al. 2017;Gramowski et al. 2011).

Lanthanides were long considered biologically inert elements, not involved in biochemical pathways. However, a recent discovery of a unique bacterial PQQalcohol dehydrogenases that require lanthanides has shed an intriguing light on the physiological actions of these metals (Chistoserdova 2019, Wehrmann et al. 2017; $\mathrm{Vu}$ et al. 2016). Moreover, there is new surprising evidence for the existence of some $\mathrm{Ce}^{3+}$-dependent methanol dehydrogenases also in protozoans and invertebrates (De Simone et al. 2018).

Lanthanide compounds frequently have magnetic, catalytic and optic properties and therefore they are currently widely used in industry and medicine. Since both metallic lanthanides and their numerous compounds show an accumulating number of applications, there is an increased possibility of contamination into tissues and organs, potentially affecting metabolic processes. Of particular note, gadolinium- 
based contrast agents are currently widely used in the MRI diagnostics of both the CNS and peripheral organs due to their high magnetic moment (Kanda et al. 2014; Adding et al. 2006). These standard paramagnetic contrast agents are considered safe and non-genotoxic, however some patients with preexisting renal disease have reported symptoms of nephrogenic systemic fibrosis or gadolinium deposition disease (Lyapustina et al. 2018; Goischke 2017; Perazella and Rodby 2007). Although brain depositions of mainly linear gadolinium contrasts may also occur, any adverse health effects or structural abnormalities associated with these compounds in the human CNS have so far not been reported (Chehabeddine et al. 2019; Choi and Moon 2019; El-Khatib et al. 2018). Interestingly, a high resolution small animal MRI study revealed that a thulium-based macrocyclic complex may be an accurate sensor of temperature and $\mathrm{pH}$ in the rat brain (Coman et al. 2009). The luminescent marker, europium-albumin can be applied to examine blood-brain barrier permeability in experimental lipopolysaccharide induced meningitis (Ivey et al. 2005). Europium- superparamagnetic iron oxide particles may be also useful for recent studies on the role of the brain choroid plexus in the mechanism of monocyte movement during neuroinflammatory processes (Milward et al. 2017). Europium probes can bind selectively to some drug sites on human serum proteins that suggests their potential usefulness in current diagnostics and basic pharmacological studies (Shuvaev et al. 2016).

The potential therapeutic applications of the lanthanides, primarily based on their similarity to calcium, have been the basis for research since the early part of the twentieth century (Zhang et al. 2011;Fricker et al. 2006). Currently, cerium nitrate is used as a cream with silver sulfadiazene for the treatment of burns (Vitse et al. 2018; Oen et al. 2012). Lanthanum carbonate (Fosrenol), acts as a phosphate binding agent and has been approved for the treatment of hyperphosphatemia in renal dialysis patients and in calciphylaxis (Aaseth and Bjørke-Monsen 2018; Chan et al. 2014). A lanthanide texaphyrin complex (motexafin gadolinium) has been evaluated in Phase III clinical trials for the treatment of brain metastases in non-small cell lung cancer (Mehta et al. 2009). It is also worth noting, that lanthanide radionuclides; ${ }^{166} \mathrm{Ho}$ (usually in a chitosan biodegradable complex form), ${ }^{169} \mathrm{Yb},{ }^{170} \mathrm{Tm}$ and ${ }^{177}$ Lu are often applied in oncological brachytherapy in various organs $(\mathrm{Ha}$ et al. 2013; Krishnamurthy et al. 2011; Escala-Cornejo et al. 2018). 
Accumulating reports show that lanthanides may affect several aspects of neuronal physiology and brain function through regulating the opening of ion channels, modulating synaptic transmission or potentially modifying cellular oxidative equilibrium. As lanthanide ions are able to cross the blood-brain barrier, the toxicological properties of these elements also merit attention. However, despite these potential drawbacks there are a number of recent suggestions that lanthanide oxides, in the form of nanoparticles, may have unique and clinically promising neuroprotective properties under conditions such as ischemic brain injury. We have therefore comprehensively reviewed the growing literature on lanthanides focusing on their role in neuronal physiology.

2. Lanthanides as modulators of neuronal ion channel physiology

Due to the aforementioned molecular analogy with calcium, lanthanide ions have been shown to affect the activity of some neuronal membrane channels, including ionotropic receptors in both the central and peripheral nervous system (Fig.2.). Indeed, numerous metal ions, including lanthanides may modify channel gating or block ion currents (Elinder and Arhem 2003). Because of its uniquely strong gating activity, $\mathrm{La}^{3+}$ is sometimes called a "supercalcium" (Brown et al. 1990) and the effects of lanthanides on voltage-gated ion channels including potassium and calcium have been previously reported in diverse cell types (Pałasz and Czekaj 2000). Trivalent lanthanide cations directly block ion flow through neuronal voltagegated $\mathrm{K}^{+}$channels (VGKC) with a potency that varies inversely with the ionic radius (Alshuaib et al. 2005, Enyeart 1998). However, the suppression of $\mathrm{K}^{+}$flow by lanthanides seems to be regulated by an alternative mechanism to traditional channel pore occlusion. Lanthanides reduce $\mathrm{K}^{+}$currents by altering voltagedependent gating and modifying ion interactions with $\mathrm{Ca}^{2+}$ unspecific binding sites (Watkins and Mathie 1994). A number of non-voltage-gated $\mathrm{K}^{+}$channels are also blocked by $\mathrm{La}^{3+}$ and $\mathrm{Gd}^{3+}$ (Lesage and Lasdunski 2000; Patel and Honore 2001) and an inward rectifier $\mathrm{K}^{+}$channel in rat corticotropes is in turn insensitive to $\mathrm{La}^{3+}$ (Kuryshev 1997). Lanthanides can interact with the $\mathrm{Ca}^{2+}{ }^{2+}$ binding sites of both $\mathrm{T}$ and $L$ channels, while calcium-specific or nonspecific lanthanide-binding sites have been 
identified in the structure of some receptors e.g. glutamate mGluR, acetylcholine and insulin (Pałasz and Czekaj 2000). The blockade of low-voltage-activated T-type $\mathrm{Ca}^{2+}$ channels by lanthanides is caused by pore occlusion with a potency that varies inversely with ionic radius (Mlinar and Enyeart 1993); while L-type $\mathrm{Ca}^{2+}$ channel inhibition directly correlates with the radius (Lansman 1990). $\mathrm{La}^{3+}$ may also enhance $\mathrm{Na}^{+}$current $\left(I_{\mathrm{Na}}\right)$ of the voltage-gated sodium channel (VGSC) in isolated rat hippocampal CA1 neurons, thus shifting the activation curve to positive potential and decrease neuronal excitability (Du and Yang 2009). This effect was concentration and voltage-dependent and abolished by both $\mathrm{La}^{3+}$ elimination and wash out. One can therefore hypothesize, that the $\mathrm{La}^{3+}$ binding site is located extracellularly to the sodium channel. Of note, lanthanum may increase the $I_{\mathrm{Na}}$ activation even at very low micromolar concentrations (Du and Yang 2009).

$\gamma$-aminobutyric acid (GABA) receptor-dependent pathways are believed to establish the main inhibitory system of the brain. $\mathrm{La}^{3+}$ affects $\mathrm{GABA}_{\mathrm{A}}$ and increases receptor affinity to the agonist through special domain binding at the chloride channel, distinct from that of picrotoxin, barbiturates, benzodiazepines, $\mathrm{Cu}^{2+}$ and $\mathrm{Zn}^{2+}$. This mode of action was described in the pyramidal neurons of hippocampal CA1 area where $\mathrm{La}^{3+}$ increases $\mathrm{GABA}_{\mathrm{A}}$ affinity to the ligand and potentiates GABAactivated currents (Boldyreva 2005). Lanthanides with higher atomic numbers also have stimulatory effects, the potency of which increases with atomic number. For instance, a study on cultured rat dorsal root ganglion neurons has shown that $\mathrm{Tb}^{3+}$ prolongs the opening time of the $\mathrm{GABA}_{\mathrm{A}}$ chloride channel (Narahashi et al.1994, Ma and Narahashi 1993). An increased $G_{A B A}$ sensitivity and enhanced chloride current after $\mathrm{La}^{3+}$ administration is also reported for isolated cerebellar Purkyne cells (Kolbaev et al. 2002). It is therefore likely that $\mathrm{Tb}^{3+}$ binds to the allosteric active site of the $\mathrm{GABA}_{\mathrm{A}}$ receptor-ion channel complex, extending its mean opening time by increasing the affinity of GABA (Ma et al., 1994). Lanthanides potentiate the GABA response and this effect may vary inversely to the radii of their hydrated ion hence the opening time of the channel and the amplitude of the lanthanide-induced voltage decreases with the atomic number as follows: $\mathrm{Lu}^{3+}>\mathrm{Er}^{3+}>\mathrm{Tb}^{3+}>\mathrm{Eu}^{3+}>\mathrm{Nd}^{3+}>\mathrm{Ce}^{3+}>$ $\mathrm{La}^{3+}$ (Ma et al., 1993). Conversely, a voltage clamp study has shown no correlation between the size of the lanthanide ion and the magnitude of the $G A B A_{A}$ current evoked by $\mathrm{La}^{3+}, \mathrm{Ce}^{3+}, \mathrm{Nd}^{3+}, \mathrm{Gd}^{3+}, \mathrm{Tb}^{3+}, \mathrm{Er}^{3+}$ and $\mathrm{Yb}^{3+}$ acting on the $\mathrm{GABA}_{\mathrm{A}}$ receptor 
of cholinergic neurons in rats (Kumamoto and Murata, 1996). Another study shows that $\mathrm{GABA}_{\mathrm{A}}$-dependent chloride influx to cultured rat cerebellum granule cells was inhibited by $\mathrm{La}^{3+}$ (Barila et al. 2001). Lanthanum ions exhibited a potentiating influence on recombinant $\alpha_{1} \beta_{2} \gamma_{2}$ and $\alpha_{1} \beta_{3} \gamma_{2}$ but conversely inhibitory modulation of $\alpha_{6} \beta_{3} \gamma_{2}$ and $\alpha_{6} \beta_{3} \delta G A B A_{A}$ receptors (Im et al. 1992; Saxena et al. 1997). The antagonistic $\mathrm{La}^{3+}$ effect on native $\mathrm{GABA}_{A}-\mathrm{Rs}$ in mouse granule neurons is probably caused by its selective binding to $\alpha 6$ subunit (Mäkelä et al. 1999). There are also reports that $\mathrm{Gd}^{3+}$ may inhibit the $\mathrm{K}^{+}-\mathrm{Cl}^{-}$co-transporter $(\mathrm{KCC})$ function and increase intracellular chloride concentration in cultured rat spinal cord neurons. This $\mathrm{Gd}^{3+}$ action was abolished by furosemide, a blocker of both $\mathrm{KCC}$ and the $\mathrm{Na}^{+}-\mathrm{K}^{+}-\mathrm{Cl}-\mathrm{co}-$ transporter (NKCC), but not bumetanide, a specific NKCC inhibitor. It is noteworthy that $\mathrm{Gd}^{3+}$ did not block the muscimol-induced outward currents recorded by conventional whole-neuron patch-clamp technique. Hence, $\mathrm{Gd}^{3+}$ may affect the inhibitory action of brain GABA that is a consequence of relatively hyperpolarized, KCC-dependent chloride-equilibrium (ECl) potential (Ishibashi et al. 2009). Gd $^{3+}$ may decrease the amplitude of proton activated currents in isolated Purkinje cells in a dose-dependent manner, with the intensity of blockade seeming to be independent from membrane potential. Interestingly, $\mathrm{Gd}^{3+}$-related inhibition of the activated receptor was faster and stronger in comparison to the inactivated one. Lanthanide ions may therefore modulate the inhibitory output from cerebellar cortex via regulation of GABA-ergic ganglion cell physiology (Sharonova et al. 2008).

Beyond the modulation of GABA, both $\mathrm{La}^{3+}$ and $\mathrm{Gd}^{3+}$ act as potent blockers of the vanilloid-type heat-activated ion channels TRPV2 in cultured rat dorsal root ganglion neurons. This finding may help to introduce a new pharmacological tool to distinguish between heat signaling of TRPV2 and the similar capsaicin-receptor, TRPV1, which is strongly sensitized by lanthanides (Leffler et al. 2007). Of interest, $\mathrm{Gd}^{3+}$ strongly blocks stretch-sensitive ion channels (SACs) in the sarcolemma of skeletal muscle fibers (Coirault et al. 1999). Both $\mathrm{Gd}^{3+}$ and $\mathrm{La}^{3+}$ were also potent inhibitors of the lysoplasmenylcholine-induced current and equally delayed the onset of myocyte contractions in the rabbit heart, but surprisingly $\mathrm{Gd}^{3+}$ sensitive SACs were not blocked by this ion (Caldwell and Baumgarten 1998). A recent study reports that both $\mathrm{Eu}^{3+}$ and $\mathrm{Sm}^{3+}$ exhibit an agonistic affinity to both $\mathrm{Ca}^{2+}$-binding sites of the ryanodine receptor (RyR). Interestingly, the voltage-dependent properties of the 
aforementioned ion action suggests that the activating $\mathrm{Ca}^{2+}$ binding domain is located in the pore entrance of the RyR channel (Sárközi et al. 2017). Several key aspects of synaptic activity and plasticity are strictly controlled by cellular calcium homeostasis (Catterall et al., 2013; Maggio and Vlachos, 2014), therefore some neuronal mechanosensitive, $\mathrm{Ca}^{2+}$-related SACs e.g. Piezo-1 may also play, a so far understudied, role in brain function (Velasco-Estevez et al. 2018). Potentially, both SACs and transient receptor potential (TRP) channels in various types of central and peripheral sensory neurons may be blocked by $\mathrm{Gd}^{3+}$ (Mueller-Tribbensee et al. 2015). Among the mammalian transient receptor potential channels (TRPCs) with a $\mathrm{Ca}^{2+}$-permeable pore, only two isoforms TRPC4 and TRPC5 are potentiated by $\mathrm{La}^{3+}$ (Jun et al. 2003; Schaeffer 2002), others (TRPC 1-3, and 6-7) are in turn blocked by both $\mathrm{La}^{3+}$ and $\mathrm{Gd}^{3+}$ (Riccio et al. 2002; Inoue et al. 2001). Interestingly it has also been demonstrated that pretreatment with $\mathrm{Gd}^{3+}$ attenuated ischemia/reperfusioninduced infarct size in rats by the blockage of stretch-activated calcium channels (Gulati et al., 2013).

3. Lanthanide action in neurotransmitter release machinery and synaptic function

Lanthanide ions have long been reported to influence synaptic physiology as well as mechanisms of neurotransmitter exocytosis in various types of neurons (Fig.2.). Almost 50 years ago Ricardo Miledi from University College London perceived that $\mathrm{La}^{3+}$ are able to block calcium-related neurotransmission (Miledi 1971). Cytophysiological effects of lanthanides result largely from the fact that the sizes of their ionic radii are comparable to that of $\mathrm{Ca}^{2+}$ enabling them to compete with calcium at various steps of the synaptic transmission process. It was initially reported that $\mathrm{La}^{3+}, \mathrm{Gd}^{3+}$ and $\mathrm{Lu}^{3+}$ at a concentration of $100 \mathrm{nM}-100 \mu \mathrm{M}$ can directly trigger the release of neurotransmitters (Vaccari et al., 1999) but $\mathrm{La}^{3+}$ blocks the $\mathrm{Ca}^{2+-}$ dependent pathway of exocytosis (Przywara et al., 1992; Vaccari et al., 1999). Possibly, $\mathrm{La}^{3+}$ inhibits the binding of $\mathrm{Ca}^{2+}$ to the synaptosome membrane, decreases the neural $\mathrm{Ca}^{2+}$ and $\mathrm{Mg}^{2+}$ ATPase activity (Basu et al. 1982). However, lanthanide ions cannot replace $\mathrm{Na}^{+}$in its neuronal channels. Later studies indicated that fast triggering of SNARE-related neurotransmitter release by lanthanum is not dependent 
of $\mathrm{La}^{3+}$ influx into neurons (Chung et al. 2008). Potentially, $\mathrm{La}^{3+}$ activates an extracellular domain by binding to a presumable presynaptic receptor e.g. glutamate mGluR or nonselective calcium channels (Chung et al. 2008, Smith et al. 2004). Metabotropic GluRs possess binding sites for lanthanides (Abe et al. 2003), thus, the rapid effect of $\mathrm{La}^{3+}$ can be also mediated by intracellular $\mathrm{Ca}^{2+}$ release from endoplasmic stores. The most noteworthy feature of rapid $\mathrm{La}^{3+}$-triggered neurotransmitter exocytosis is a very strict dependence on synaptobrevin-2 (VAMP2) presynaptic protein. In murine hippocampal cultured neurons, lack of synaptobrevin-2, but not synaptotagmin-1, silenced the rapid action of $\mathrm{La}^{3+}$ in the presynaptic terminal, however the delayed neurotransmitter release was still visible (Chung et al. 2008). This seems rather unexpected given other calcium-related neurotransmitter release cannot be fully blocked in synaptobrevin-2-deficient neurons. Probably, $\mathrm{La}^{3+}$ may act at an extracellular site to initiate rapid SNAREdependent neurotransmission, whereas delayed exocytosis may be caused by slow $\mathrm{La}^{3+}$ influx into the neuron (Chung et al. 2008). The multi-faceted activity of $\mathrm{La}^{3+}$ at the level of the presynaptic neurochemical machinery might be connected with neurotoxic effects occurring after long-term exposure to soluble lanthanum salts (Feng et al. 2006). On the other hand $\mathrm{Gd}^{3+}$ ions trigger calcium-independent neurotransmitter release in a dose-dependent manner and facilitate spontaneous release of the glutamate analogue [3H]D-aspartate. It may suggest that lanthanides induce a vesicular neurotransmitter exocytosis by the mechanisms common for all transitional metals (Lopatina et al. 2005), e.g. $\mathrm{Gd}^{3+}$ and $\mathrm{La}^{3+}$ trigger neurotransmitter release in rat brain synaptosomes. Interestingly the application of RGDS peptide, an inhibitor of integrins, significantly decreased $\mathrm{Gd}^{3+}$-induced aspartate release with no effect upon hypertonicity-evoked fusion. Genistein, a selective blocker of tyrosine kinases; and citrate, an inhibitor of lanthanides-dependent aggregation, did not abolish the neurotransmitter exocytosis. It suggests that integrins contribute to the $\mathrm{Gd}^{3+}$-evoked aspartate release (Waseem et al. 2008). Interestingly, $\mathrm{Eu}^{3+}$ may inhibit the cellular uptake of norepinephrine acting as NERT blocker (Bryan-Lluka and Bonish, 1997).

Glutamate signaling plays a fundamental role in the neurochemistry of memory, cognitive tasks, attention, affective control and developmental synaptogenesis (Robbins and Murphy 2006; Deng et al. 2007). Recent findings prove that lanthanides may affect the NMDA receptor-related long-term potentiation 
(LTP) in the rat hippocampal CA1 neurons and damage spatial learning and memory. For instance, $\mathrm{La}^{3+}$ increased NMDA receptor NR1, NR2A and NR2B subunit expression that may impair cognitive and memory processes (Hu et al. 2018; Du et al. 2015). The expressions of glutamate/aspartate transporters (GLAST and GLT-1), glutamine syntethase (GS) and phosphate-activated glutaminase (PAG) were decreased. This NMDA receptor overactivation causes glutamate-induced excitotoxic neuronal injury and is usually connected with $\mathrm{Ca}^{2+}$ excess and apoptosis (Sun et al. 2018a).

Furthermore, disturbed intracellular calcium balance may disintegrate mitochondrial physiology and eventually trigger apoptosis. Lanthanum-related neurotoxicity may also be due to modulation of NO-cGMP signaling mechanisms; La3+ ions increase both calcium and glutamate levels in the rat hippocampus. A dose-dependent increase of inducible nitric oxide synthase (iNOS) expression as well as elevated NO and cGMP levels were also observed (Du et al. 2015). La ${ }^{3+}$ and $\mathrm{Gd}^{3+}$ are also antagonists of AMPA and kainate glutamatergic receptors (KARs) in cultured rat hippocampal, cortical and dorsal root ganglion neurons, possibly due to their direct interaction with the ligand molecule rather than competitive antagonism or channel pore blockade (Hong et al. 2004, Huettner et al., 1998). Interestingly, AMPA receptors require around 20-times higher concentrations of lanthanide ions (100 micromoles) for their half-maximal blockade than KARs. $\mathrm{Gd}^{3+}$ potently reduces AMPA receptor desensitization and exposes some properties of the positive modulators of AMPA-R activity (Lei and MacDonald 2001). $\mathrm{La}^{3+}$ may also distinctly reduce $p-I K K \alpha / \beta$ and $p-I k B \alpha$ in the rat hippocampus that inhibit the NF- $\mathrm{KB}$ signaling pathway. Because NF-KB signaling appears to be involved in the process of memory consolidation (O'Sullivan et al. 2010), it should not be excluded that learning impairment observed in rats exposed to $\mathrm{La}^{3+}$ is due to inhibition of this regulatory system. Indeed, the highly decreased expression of c-Fos, c-jun and BDNF seems to support this hypothesis (Zheng et al. 2013). A La ${ }^{3+}$-dependent impairment of hippocampal memory processing may be also associated with a suppression of the ERK/MSK1 signaling system and presence of significant abnormalities in the synaptic ultrastructure e.g. non-uniform membrane curvature and flattened postsynaptic density (Liu et al. 2014). 
On the other hand, a recent report suggests that these cognitive disturbances may be additionally enhanced by neuronal autophagy process in hippocampal neurons. Possibly, $\mathrm{La}^{3+}$ generates oxidative stress that activates $\mathrm{JNK} / \mathrm{C}$-Jun and JNK/FoxOs but supresses AKT/mTOR signaling pathways and eventually promotes the origin of autophagosomes (Gao et al. 2019). It should also be taken into account that La-dependent memory and learning deficits can be related to the inhibition of astrocyte-neuron lactate shuttling in the hippocampal neurons, caused mainly by the downregulation of astrocyte monocarboxylate transporter 1, 2 and 4 (MCT 12 and 4) expression and a decrease in lactate dehydrogenase (LDH) content and activity (Jin et al. 2017). A suppression of lactate turnover in astrocytes may therefore be considered as an alternative mechanism of the potentially neurotoxic action of $\mathrm{La}^{3+}$ in the brain (Sun et al. 2018b).

\section{Lanthanides and neuronal oxidative stress}

Oxidative stress is a complex and dynamic process of cellular deterioration, caused by an imbalance between the generation of reactive oxygen species (ROS) and the availability and action of superoxide scavengers or other antioxidant factors (Du et al., 2009). It is well known that aerobic cells are susceptible to the effects of oxidative stress. However, the central nervous system is especially vulnerable to the action of ROS due to different causes and mechanisms, including: high consumption of oxygen to carry out physiological processes (about 20\% of the bloodstream oxygen), high composition of polyunsaturated fatty acid and the selectivity of the blood-brain barrier which reduces the diffusion of some antioxidants such as vitamin E tocopherols (Schula et al., 2011). ROS levels in oxidative stress trigger processes of neurodegeneration and cell death, mainly affecting mechanisms of lipid peroxidation and structural damage to proteins and DNA (Markesbery et al., 2007). In the last decade, oxidative stress has been associated with neurodegenerative diseases such as Alzheimer's disease (Lovell and Markesbery, 2007), Parkinson's disease (Nikam et al., 2009; Zhou et al., 2008) and amyotrophic lateral sclerosis (Chi et al., 2007); disorders of the autistic spectrum (Gónzalez-Fraguela et al., 2013) and neuronal hyperexcitation (Cardenas-Rodriguez et al., 2013). 
As mentioned above, lanthanides present different applications in agriculture, technological industry, pharmacology and biomedicine, due to the diversity of their physical, chemical and biological effects. However, the effects of their accumulation on the human body are still controversial, especially at the level of the central nervous system. In this regard, Zhao et al (2011) demonstrated that three lanthanides produced direct or indirect injury to the mouse brain. In this study, mice were injected with $\mathrm{LaCl}_{3}, \mathrm{CeCl}_{3}$ and $\mathrm{NdCl}_{3}$ in the abdominal cavity and monitored for migration, with the compounds detected in the forebrain, causing nervous tissue damage, oxidative stress and subsequently altering the normal metabolism of neurochemicals. $\mathrm{La}^{3+}, \mathrm{Ce}^{3+}$ and $\mathrm{Nd}^{3+}$ increased both $\mathrm{ROS}$ production and lipid peroxidation. Brain activities of the main endogenous antioxidant enzymes: superoxide dismutase (SOD), catalase, ascorbic acid and glutathione peroxidases (APx, GSH-Px) were in turn strongly reduced (Zhao et al. 2011, Fig.3.).

Posterior studies (Yang et al. 2013) also found that in the hippocampus of rats exposed to $\mathrm{LaCl}_{3}$ a neuronal deterioration and increased level of apoptosis occurred. This was mainly due to an elevation in the glutamate and intracellular $\mathrm{Ca}^{2+}$ concentrations and in the ratio between proapoptotic Bax and antiapoptotic Bcl-2 protein ( $\mathrm{Wu}$ et al. 2013). $\mathrm{La}^{3+}$ may therefore affect the neuronal excitability, neurotransmitter turnover and metabolic pathways via oxidative stress and cholinergic signaling impairment. Of note, $\mathrm{La}^{3+}$ may increase ROS concentration and trigger apoptosis in neuroglia. It was found that $\mathrm{La}^{3+}$ downregulated Nrf2 gene expression and reduced the activity of SOD, dehydrogenase quinone 1 (NQO1), heme oxygenase-1 (HO-1), glutathione peroxidase 1 (GSH-Px 1 ) and glutathione-stransferase (GST) in cultured rat astrocytes (Zhang et al. 2017). On the other hand, L-cysteine may be cautiously considered as a neuroprotective agent against chronic, potentially toxic exposure to soluble lanthanide compounds (Liapi et al. 2009).

It was also found that intragastric administration of $\mathrm{CeCl}_{3}$ to mice significantly affected learning ability, due to an alteration in homeostasis of trace elements, enzymes and neurotransmitters in the brain (Zha et al. 2011). Cerium compounds are increasingly used in industry, including fertilizers and have been shown to enter the ecological environment and human body via food chains ( $\mathrm{Ni}, 2002$; $\mathrm{Hu}$; et al.; 2004; Kostova, 2005), It is therefore paramount to understand potential long-term neurotoxic effects. Another study by Zhe et al. (2013) reports that the exposure of $\mathrm{CeCl}_{3}$ in mice increases oxidative stress in the hippocampus, besides altering 154 
genes involved in multiple processes such as learning and memory, programmed neuron death, response to stress, immunity and inflammation. A study by Cheng et al. (2013) reports that long-term exposure to $\mathrm{CeCl}_{3}$ supports ROS production and triggers apoptosis in the mouse hippocampus. $\mathrm{Ce}^{3+}$ significantly increased the expression of apoptosis-related genes e.g. antagonizing transcription factor (TRB), ubiquitin-conjugating enzyme e2 (UBE2V1), cysteine-serine-rich nuclear protein1 (AXUD1) and cell division 37 homolog (CDC37). The expression of several genes involved in the neurochemistry of memory and learning such as Fos, Adcy 8 and Slc5a7 were in turn down-regulated. Indeed, a significant impairment of spatial recognition memory also occurred (Cheng et al. 2013). All mentioned genes are therefore considered as potential biomarkers of lanthanides neurotoxicity.

Gadolinium, a lanthanide whose derivatives have been widely used as a contrast medium in magnetic resonance (Adding et al., 2006), has been shown to induce the generation of ROS in human liver cells (Liu et al., 2003). A study by Xia et al (2011) confirmed that the oxidative stress caused by this element triggers the stress of the endoplasmic reticulum in rat cortical neurons, causing neuronal death, mainly due to a significant increase in $\mathrm{Ca}^{2+}$ concentration. $\mathrm{Gd}^{3+}$ supports the $\mathrm{ROS}$ origin in neurons but the mechanism of their action is different from that of $\mathrm{La}^{3+}$ (Dong et al. 2009) and the greater studied more toxic ions e.g. $\mathrm{Al}^{3+}$ and $\mathrm{Cd}^{2+}$ (Toimela and Tähti 2004; Niu et al. 2005). Furthermore, $\mathrm{Gd}^{3+}$ does not bind to thiol groups and has no significant redox activity. It is likely, that $\mathrm{Gd}^{3+}$ may affect the endoplasmic reticulum IRE1-XBP1, PERK and ATF6 pathways, increase GRP78 expression that finally induces an unfolded protein response (UPR) signaling route. These molecular events activate CCAAT/enhancer binding protein homologous protein (CHOP or Gadd153) and trigger apoptosis (Xia et al.2011). Interestingly, the $\mathrm{N}$-acetylcysteine application may eliminate oxidative neurotoxic effects of $\mathrm{Gd}^{3+}$.

On the other hand, new drugs containing lanthanide ions have appeared in the pharmaceutical industry in recent years, based on the similarity of their biological properties with calcium. It has been observed that lanthanides can act as antioxidants or pro-oxidants, depending on the environment, nature of binding and tissue concentration. Their strong affinity to reactive oxygen species intervenes in the elimination of free radicals, producing non-toxic compounds and exerting antioxidants in vivo. However, this property is in turn responsible for the competitive binding of lanthanides to proteins, altering several biologically relevant electron 
transfer pathways and finally resulting in toxicity (Valcheva-Traykova et al., 2014). More research is therefore needed for their application in the field of medicine, since its use requires a positive balance between antioxidant activity and toxic effects.

5. Neuroprotective properties of lanthanide oxides nanoparticles

One of the most intriguing properties of lanthanides is their neuroprotective effect - ability to protect different cells from various forms of dangerous oxidative and nitrosative stress present in pathological conditions by its modulation (Fig.4.). Conventional antioxidants that are currently available scavenge a single free radical before they are destroyed in the process, so there is a pressing need to find novel targets with therapeutic potential. Most researchers have focused on neuroprotective and pharmaceutical properties of cerium oxide $\left(\mathrm{CeO}_{2}\right)$ nanoparticles (CeNPs), also known as nanoceria, which are widely used as inorganic catalysts in industrial material applications, because of their potent free radical-scavenging properties via dual oxidation state (Rzigalinski et al., 2017). Nanoceria are able to either donate or receive electrons as they alternate between the +3 and +4 valence states and their catalytic activities mimic those of the neuroprotective enzymes superoxide dismutase and catalase.

A breakthrough study was published by Schubert et al. (2006), where nanoparticles composed of cerium oxide or yttrium oxide were seen to protect nerve cells from oxidative stress, with neuroprotection independent of particle size. The researchers established that both types of lanthanide nanoparticles act as direct inorganic antioxidants to limit the amount of reactive oxygen species required to kill cells. Two years later it was experimentally proven that the application of a single dose of nanoceria at a nanomolar concentration is biocompatible, regenerative and provides a significant neuroprotective effect on adult rat spinal cord neurons (Das et al., 2008). The possibility of nanoceria application to prevent ischemic insult was also suggested from an oxidative injury assay. Estevez et al. (2011) took up this research problem and have explored the use of nanoceria as a potential therapeutic agent for stroke using animal model of cerebral ischemia. They found that ceria nanoparticles reduce ischemic cell death by approximately $50 \%$. This effect was caused by reduction of superoxide $(\mathrm{O}(2)(\cdot-))$ and nitric oxide concentrations, decrease of the ischemia-induced 3-nitrotyrosine levels and a modification of tyrosine residues in 
proteins affected by the peroxynitrite radicals, which are crucial in the dissemination of oxidative injury in biological tissues.

Nanoceria's efficacy in neutralizing biologically generated free radicals has been tested also by the Heckman et al. (2013). They report the in vivo characteristics of CeNPs, with $\sim 4.0 \mathrm{~h}$ half-life, in an animal model of immunological and free-radical mediated oxidative injury leading to neurodegenerative disease (mice with a murine model of multiple sclerosis). The administered intravenously CeNPs were well tolerated, able to penetrate the brain, reduce reactive oxygen species levels, and alleviate clinical symptoms and motor deficits. Ciofani et al. $(2013,2014)$ have published two articles based on their studies on the PC12 cell line that represents a valuable model for many features of central dopaminergic neurons. As it was expected nanoceria confirmed a potent anti-reactive oxygen species action but, interestingly, also showed beneficial effects on both neuron-like cell differentiation and dopamine production. Experimental evidences at a gene level reveal that CeNPs modulate transcription of genes involved in natural cell defenses, downregulate genes involved in inflammatory processes, and up-regulate some genes involved in neuroprotection. Nanoceria may also be potentially helpful in the treatment of Alzheimer's disease, because its well known that nitrosative stress caused by peroxynitrite and mitochondrial dysfunction participate in the pathogenesis of this disorder. Application of CeNPs reduces levels of reactive nitrogen species, protein tyrosine nitration $A \beta$-induced mitochondrial fragmentation and neuronal cell death after exposure to peroxynitrite (Dowding et al., 2014). Additionally it was presented that nanoceria are internalized by perikarya and accumulate at the mitochondrial outer membrane and plasma membrane. Assessment of the CeNPs axonal translocation conducted on the frog sciatic nerve fibers in an ex vivo preparation have demonstrated, that $\mathrm{CeO}_{2}$ nanoparticles translocate within the nerve (Kastrinaki et al., 2015). This movement depends on both axonal integrity and electrical activity and its speed is similar to the slow axonal transport rate.

Recently more attention has been focused on the role of microglia in neuropathological processes. The ability of CeNPs to mitigate neurodegeneration by microglial activation and related inflammatory processes has been studied via exposure of rats to high intensity light (Fiorani et al.2015). Nanoceria maintained retinal visual response after light-induced damage and reduced neuronal death and 
"hot spot" extension preserving outer nuclear layer morphology. There was also recently reported that a single administration of nanoceria into the vitreous body exerted long-term neuroprotective effects on rat retina (Tisi et al. 2019). These findings support the hypothesis that CeNPs may be potent therapeutic agents in retinal neurodegenerative events and correlate with a previously published study (Kong et al.2011) reporting that in the mutant mouse, which exhibits progressive cochlear and retinal degeneration, nanoceria protect the retina by decreasing reactive oxygen species, up-regulating of the neuroprotection-associated gene expression, down-regulating apoptotic signaling and/or enhancing survival pathways. Another example of usefulness and potential of CeNPs for mitigating neuropathological effects and modifying the course of recovery after injury is a study by Bailey et al. (2016). It was shown that nanoceria reduce neuronal death and calcium dysregulation after in vitro trauma, preserve endogenous antioxidant systems and decrease macromolecular free radical damage. Furthermore, it improves cognitive function in the rat model of mild lateral fluid percussion brain injury which generally is associated with oxidative stress, mitochondrial dysfunction and poor functional outcome. A neuroprotective and antioxidant role for CeNPs was well documented by Ranjbar et al. (2018) using the paraquat-induced model of oxidative stress in male rats. CeNPs in groups co-administered with paraquat significantly ameliorated lipid peroxidation, DNA damage, and caspase-3 levels while increasing antioxidant capacity and total thiol molecule contents as well as enhancing nestin and Neurod1 mRNA levels in the brain. According to the current state of neurobiological knowledge, one of the possible directions of lanthanide therapeutic action is the modulation of neurogenesis. Using polyethylene glycolcoated CeNPs, Arya et al. (2016) have evaluated the neuroprotective, as well as the cognition-enhancing activities, of nanoceria during hypobaric hypoxia via relation with generation of reactive nitrogen and oxygen species. A presence of CeNPs in the rodent brain resulted in significant reduction of oxidative stress and associated hypoxia-related injury. Moreover, nanoceria ameliorated hypoxia-induced memory impairment and stimulated neuronal survival and neurogenesis in the hippocampus.

The most recently published research concerned the anti-inflammatory properties of nanoceria (Hekmatimoghaddam et al., 2019). This study, based on the brain neuroinflammation model induced by both proteolipid protein and parathion, showed that the expression of interleukins (IL-6, 10 and 17) genes and their serum 
levels were significantly decreased after administration of gelatin hydrogel containing cerium oxide nanoparticles coated with interleukin-17. Collectively, the above studies suggest that nanoceria should be considered as very promising therapeutic agent, especially in the treatment of ischemic brain injuries and neurodegenerative diseases. However, there are still many concerns related to the pharmacological effects of CeNPs and further studies are needed to confirm their potential clinical usefulness.

\section{Concluding remarks}

The era when a few specialized scientists were exposed with lanthanide compounds are definitely over. Nowadays, due to the dynamic development of electronic technologies and modern medical diagnostics, almost everyone may be exposed to lanthanide-containing substances. Screen luminophors, strong magnets, computer memories, MRI contrast agents and even flints for lighters are everyday sources of these elements. The risk of potential penetration of lanthanides into the human body including the central nervous system is therefore significantly increased. It is likely that lanthanide ions uniquely modulate several important neurochemical processes, thus altering functions in both neurons and glial cells. The majority of cytophysiological and potentially toxic effects of lanthanides observed at the level of neuronal ion channels, receptor molecules and synaptic machinery result largely from the fact that the sizes of their ionic radii are similar to that of calcium. Some lanthanide ions are frequently applied in basic pharmacological studies as selective blockers of ionotropic receptors. Lanthanides are also considered to impair mitochondrial functions and SER functions and initiate the oxidative injuries of the nervous tissue. On the other hand, cerium and yttrium oxides in the form of nanoparticles seems to be very promising neuroprotective agents after ischemic brain injury in preclinical studies. Given, that all the aforementioned intriguing mechanisms of lanthanide effects on neuronal and glial biochemistry are still poorly understood, this field requires urgent further focus. 
References

Aaseth J., Bjørke-Monsen A.L. (2018). Lanthanum Carbonate - A New Phosphate Binding Drug in Advanced Renal Failure. Current Medicinal Chemistry 25: 113-117. doi: 10.2174/0929867324666170509125840.

Abe H., Tateyama M., Kubo Y. (2003). Functional identification of Gd3+ binding site of metabotropic glutamate receptor 1alpha. FEBS Letters 545: 233-38

Adding L. C., Gerard L. B. and Lars E. G. (2006). Basic experimental studies and clinical aspects of gadolinium salts and chelates. Cardiovascular Drug Reviews 19: 41-56.

Alshuaib W.B., Mathew M.V.(2005). Transient K+ current is blocked by lanthanum in Drosophila neurons.Neurochemical Research.30:1087-92.

Arya A., Gangwar A., Singh S.K., Roy M., Das M., Sethy N.K., Bhargava K. (2016). Cerium oxide nanoparticles promote neurogenesis and abrogate hypoxia-induced memory impairment through AMPK-PKC-CBP signaling cascade. International Journal of Nanomedicine 11:1159-73.

Bailey Z.S., Nilson E., Bates J.A., Oyalowo A., Hockey K.S., Sajja V.S.S.S, Thorpe C., Rogers H., Dunn B., Frey A.S., Billings M.J., Sholar C.A., Hermundstad A., Kumar C., Van de Vord P.J., Rzigalinski B.A. (2016). Cerium Oxide Nanoparticles Improve Outcome After In Vitro and In Vivo Mild Traumatic Brain Injury. Journal of Neurotrauma. 2016 Nov 2. doi: 10.1089/neu.2016.4644.

Barilà B., Cupello A., Robello M. (2001). Modulation by lanthanum ions of gammaaminobutyric $\operatorname{acid}(A)$ receptors of rat cerebellum granule cells in culture: clues on their subunit composition. Neuroscience Letters 298:13-16.

Basu, A., Chakrabarty, K., Chatterje, H. (1982). Neurotoxicity of lanthanum chloride in newborn chicks. Toxicology Letters 14, 21-25.

Boldyreva A.A (2005). Lanthanum potentiates GABA-activated currents in rat pyramidal neurons of CA1 hippocampal field.Bulletin of Experimental Biology and Medicine140:403-405.

Brown P. H., Rathjen A. H., Graham R. D., Tribe D. E. (1990). Rare earth elements in biological systems 92 Handbook on the Physics and Chemistry of Rare Earths Gschneidner K. A. Jr.Eyring L. Roy Elsevier North-Holland Amsterdam, Oxford

Bryan-Lluka, L., Bonish, H. (1997). Lanthanides inhibit human noradrenaline, 5hydroxytryptamine and dopamine transporters. NaunynSchmiedebergsArchieves in Pharmacology355: 699-706. 
Caldwell R.A., Baumgarten C.M. (1998). Plasmalogen-derived lysolipid induces a depolarizing cation current in rabbit ventricular myocytes. Circulatory Research 83: 533-40.

Cardenas-Rodriguez N., Huerta-Gertrudis B., Rivera-Espinosa L., MontesinosCorrea H., Bandala C., Carmona-Aparicio L. (2013). Role of oxidative stress in refractory epilepsy: Evidence in patients and experimental models. International Journal of Molecular Sciences, 14, pp. 1455-1476.

Catterall W. A., Leal K., Nanou E. (2013). Calcium channels and short-term synaptic plasticity. Journal of Biological Chemistry 288 10742-10749. doi: 10.1074/jbc.R112.411645

Chehabeddine L., Al Saleh T., Baalbaki M., Saleh E., Khoury S.J., Hannoun S. (2019). Cumulative administrations of gadolinium-based contrast agents: risks of accumulation and toxicity of linear vs macrocyclic agents. Critical Reviews in Toxicology 3:1-18. doi: 10.1080/10408444.2019.1592109.

Cheng Z., Zhao H., Ze Y., Su J., Li B., Sheng L., Zhu L., Guan N., Gui S., Sang X., Zhao X., Sun Q., Wang L., Cheng J., Hu R., Hong F. (2013).Gene-expression changes in cerium chloride-induced injury of mouse hippocampus.PLoS One. 8:e60092. doi: 10.1371/journal.pone.0060092.

Chi L., Ke Y., Luo C., Gozal D., Liu R. (2007). Depletion of reduced glutathione enhances motor neuron degeneration in vitro and in vivo. Neuroscience, 144, pp. 991-1003.

Chinopoulos C., Gerencser A.A., Doczi J., Fiskum G., Adam-Vizi V. (2004).Inhibition of glutamate-induced delayed calcium deregulation by 2-APB and La3+ in cultured cortical neurones.Journal of Neurochemistry 91: 471-83.

Chistoserdova L. (2019). New pieces to the lanthanide puzzle. Molecular Microbiology 2019 doi: $10.1111 / \mathrm{mmi} .14210$

Choi J.W., Moon W.J. (2019). Gadolinium Deposition in the Brain: Current Updates. Korean Journal of Radiology 20: 134-147. doi: 10.3348/kjr.2018.0356.

Chung C., Deák F., Kavalali E.T. (2008). Molecular substrates mediating lanthanideevoked neurotransmitter release in central synapses. Journal Neurophysiology 100 :2089-100. doi: 10.1152/jn.90404.2008.

Ciofani G., Genchi G.G., Liakos I., Cappello V., Gemmi M., Athanassiou A., Mazzolai B., Mattoli V. (2013) Effects of cerium oxide nanoparticles on PC12 neuronal-like cells: proliferation, differentiation, and dopamine secretion. Pharmacological Research 30:2133-45.

Ciofani G., Genchi G.G., Mazzolai B., Mattoli V. (2014). Transcriptional profile of genes involved in oxidative stress and antioxidant defense in PC12 cells following 
treatment with cerium oxide nanoparticles. Biochimica and BiophysicaActa. 1840:495-506.

Coirault, C., Sauviat, M.-P., Chemla, D., Pourny, J.-C., Lecarpentier, Y. (1999). The effects ofgadolinium, a stretch-sensitive channel blocker, on diaphragm muscle. European Respiratory Journal14, 1297-1303.

Coman D., Trubel H.K., Rycyna R.E., Hyder F. (2009).Brain temperature and pH measured by $(1) \mathrm{H}$ chemical shift imaging of a thulium agent. NMR in Biomedicine 22: 229-39. doi: 10.1002/nbm.1312.

Das M., Patil S., Bhargava N., Kang J.F., Riedel L.M., Seal S., Hickman J.J. (2007) Auto-catalytic ceria nanoparticles offer neuroprotection to adult rat spinal cord neurons. Biomaterials 28:1918-25.

De Simone G., Polticelli F., Aime S., Ascenzi P. (2018). Lanthanides-based catalysis in eukaryotes. IUBMB Life. 70: 1067-1075. doi: 10.1002/iub.1933.

Deng L., Yao J., Fang C., Dong N., Luscher B., Chen G.. (2007). Sequential postsynaptic maturation governs the temporal order of GABAergic and glutamatergic synaptogenesis in rat embryonic cultures. Journal of Neuroscience 27:10860-69

Dong S., Zhao Y., Liu H., Yang X., Wang K. (2009). Duality of effect of La3+ on mitochondrial permeability transition pore depending on the concentration.Biometals. 22:917-26. doi: 10.1007/s10534-009-9244-1

Dowding JM, Song W, Bossy K, Karakoti A, Kumar A, Kim A, Bossy B, Seal S, Ellisman MH, Perkins G, Self WT, Bossy-Wetzel E. Cerium oxide nanoparticles protect against $A \beta$-induced mitochondrial fragmentation and neuronal cell death. Cell Death and Differentiation. 2014;21(10):1622-32.

Du H., Yang P. (2009). Enhancement of lanthanum (III) on sodium currents in acutely isolated hippocampal CA1 neurons of rat. Neurochemical Research 34: 1562-67doi: 10.1007/s11064-009-9944-5

Du Y., Yang J., Yan B., Bai Y., Zhang L., Zheng L., Cai Y. (2015). Lanthanum enhances glutamate-nitric oxide-3',5'-cyclic guanosine monophosphate pathway in the hippocampus of rats.Toxicology and Industrial Health. 32:1791-800. doi: $10.1177 / 0748233715590517$.

Du, Z. X., Zhang, H. Y., Meng, X., Guan, Y., \& Wang, H. Q. (2009). Role of oxidative stress and intracellular glutathione in the sensitivity to apoptosis induced by proteasome inhibitor in thyroid cancer cells. BMC cancer, 9(1), 56.

Elinder F., Arhem P. (2003). Metal ion effects on ion channel gating. Quarterly Reviews od Biophysics36:373-427.

El-Khatib A.H., Radbruch H., Trog S., Neumann B., Paul F., Koch A., Linscheid M.W., Jakubowski N., Schellenberger E. (2018). Gadolinium in human brain sections and colocalization with other elements. Neurology Neuroimmunology Neuroinflammation. 19:e515. doi: 10.1212/NXI.0000000000000515. 
Escala Cornejo R.A., García-Talavera P., Navarro Martin M., Pérez López B., García Muñoz M., Tamayo Alonso M.P., Cruz Hernández J.J. (2018).Large cell neuroendocrine carcinoma of the lung with atypical evolution and a remarkable response to lutetium Lu 177 dotatate.Annals of Nuclear Medicine. 32 :568-572. doi: 10.1007/s12149-018-1276-6.

Estevez A.Y., Pritchard S., Harper K., Aston J.W., Lynch A., Lucky J.J., Ludington J.S., Chatani P., Mosenthal W.P., Leiter J.C., Andreescu S., Erlichman J.S. (2011) Neuroprotective mechanisms of cerium oxide nanoparticles in a mouse hippocampal brain slice model of ischemia. Free Radical Biology and Medicine 51:1155-63.

Feng L., Xiao H., He X., Li Z., Li F., Liu N., Zhao Y., Huang Y., Zhang Z., Chai Z. (2006). Neurotoxicological consequence of long-term exposure to lanthanum. Toxicology Letters 165:112-20.

Fiorani L, Passacantando M, Santucci S, Di Marco S, Bisti S, Maccarone R. Cerium Oxide Nanoparticles Reduce Microglial Activation and Neurodegenerative Events in Light Damaged Retina. PLoS One. 2015;10(10):e0140387.

Fricker S.P. (2006).The therapeutic application of lanthanides. Chemical Society Reviews. 35:524-33.

Gao X., Yang J., Li Y., Yu M., Liu S., Han Y., Lu X., Jin C., Wu S., Cai Y. (2019). Lanthanum chloride induces autophagy in rat hippocampus through ROS-mediated JNK and AKT/mTOR signaling pathways.Metallomics. doi: 10.1039/c8mt00295a.

Goischke H.K. (2017).Safety assessment of gadolinium-based contrast agents (GBCAs) requires consideration of long-term adverse effects in all human tissues.Multiple Sclerosis Journal - Experimental, Translational and Clinical 3(2): 2055217317704450. doi: 10.1177/2055217317704450.

González-Fraguela M., Díaz-Hung M., Vera H., Maragoto C., Noris E., Blanco L. (2013). Oxidative stress markers in children with autism spectrum disorders. British Journal Of Medical and Health Research, 3, pp. 307-317

Gramowski A., Jügelt K., Schröder O.H., Weiss D.G., Mitzner S. (2011). Acute functional neurotoxicity of lanthanum(III) in primary cortical networks. Toxicology Sciences 120:173-83. doi: 10.1093/toxsci/kfq385.

Gulati P, Muthuraman A, Jaggi AS, Singh N.Neuroprotective effect of gadolinium: a stretch-activated calcium channel blocker in mouse model of ischemia-reperfusion injury. NaunynSchmiedebergs Arch Pharmacol. 2013;386(3):255-64.

Gulyaev S.M., Ubasheev I.O., Kozhevnikova N.M. (2008).Morphological assessment of the cerebroprotective action of lanthanum acetate in chronic cerebral ischemia in rats.Neuroscience and Behavioral Physiology 38:747-50. doi: 10.1007/s11055-0089041-2.

Ha E.J., Gwak H.S., Rhee C.H., Youn S.M., Choi C.W., Cheon G.J. (2013). Intracavitary radiation therapy for recurrent cystic brain tumors with holmium-166-

This article is protected by copyright. All rights reserved. 
chico : a pilot study. Journal of Korean Neurosurgery Society 54:175-82. doi: 10.3340/jkns.2013.54.3.175

Heckman K.L., De.Coteau W., Estevez A., Reed K.J., Costanzo W., Sanford D., Leiter J.C., Clauss J., Knapp K., Gomez C., Mullen P., Rathbun E., Prime K., Marini J., Patchefsky J., Patchefsky A.S., Hailstone R.K., Erlichman J.S. (2013)Custom cerium oxide nanoparticles protect against a free radical mediated autoimmune degenerative disease in the brain. ACS Nano. 7:10582-96.

Hekmatimoghaddam S., Iman M., ShahdadiSardo H., Jebali A. (2019) Gelatin hydrogel containing cerium oxide nanoparticles covered by interleukin-17 aptamar as an anti- inflammatory agent for brain inflammation. Journal ofNeuroimmunology326:79-83.

Hong Z., Wang D.S., Lu S.Y., Li J.S. (2004).Suppression of kainate-evoked AMPA receptor mediated responses by lanthanum in rat sacral dorsal commissural neurons. Neurosignals 13: 258-64.

Hu X., Yang J., Sun Y., Gao X., Zhang L., Li Y., Yu M., Liu S., Lu X., Jin C., Wu S., Cai $Y$. (2018). Lanthanum chloride impairs memory in rats by disturbing the glutamate-glutamine cycle and over-activating NMDA receptors. Food and Chemical Toxicology 113:1-13. doi: 10.1016/j.fct.2018.01.023.

Huettner, J., Stack, E. \&Wilding, T. (1998). Antagonism of neuronal kainate receptors by lanthanum and gadolinium. Neuropharmacology 37, 1239-1247.

Im M.S., Hamilton B.J., Carter D.B., Im W.B. (1992). Selective potentiation of GABAmediated $\mathrm{Cl}$ - current by lanthanum ion in subtypes of cloned GABAA receptors.Neuroscience Letters 144:165-68.

Inoue R., Okada T., Onoue H., Hara Y., Shimizu S., Naitoh S., Ito Y., Mori Y. (2001). The transient receptor potential protein homologue TRP6 is the essential component of vascular alpha(1)-adrenoceptor-activated $\mathrm{Ca}(2+)$-permeable cation channel.Circulatory Research 88:325-32.

Ishibashi H., Hirao K., Yamaguchi J., Nabekura J. (2009). Inhibition of chloride outward transport by gadolinium in cultured rat spinal cord neurons. Neurotoxicology 30:155-59. doi: 10.1016/j.neuro.2008.10.003. Epub 2008 Oct 22.

Ivey N.S., Martin E.N. Jr, Scheld W.M., Nathan B.R. (2005). A new method for measuring blood-brain barrier permeability demonstrated with Europium-bound albumin during experimental lipopolysaccharide (LPS) induced meningitis in the rat. Journal of Neuroscience Methods. 142: 91-95.

Jin C., Gao L., Li Y., Wu S., Lu X., Yang J., Cai Y. (2017).Lanthanum damages learning and memory and suppresses astrocyte-neuron lactate shuttle in rat hippocampus. Experimental Brain Research 235:3817-3832. doi: 10.1007/s00221017-5102-5. 
Jung S., Mühle A., Schaefer M., Strotmann R., Schultz G., Plant T.D. (2003).Lanthanides potentiate TRPC5 currents by an action at extracellular sites close to the pore mouth.Journal of Biological Chemistry 278: 3562-71

Kanda T., Ishii K., Kawaguchi H., Kitajima K., Takenaka D. (2014). High signal intensity in the dentate nucleus and globus pallidus on unenhanced T1-weighted MR images: relationship with increasing cumulative dose of a gadolinium-based contrast material. Radiology $27: 834-41$.

Kastrinaki G., Samsouris C., Kosmidis E.K., Papaioannou E., Konstandopoulos A.G., Theophilidis G. (2015) Assessing the axonal translocation of $\mathrm{CeO} 2$ and $\mathrm{SiO} 2$ nanoparticles in the sciatic nerve fibers of the frog: an ex vivo electrophysiological study. International Journal of Nanomedicine 10:7089-96.

Kolbaev S.N. (2002).Modulation of GABA-activated currents in rat isolated cerebellar neurons by lanthanum ions.Bulletin of Experimental Biology and Medicine 133:4447.

Kong L., Cai X., Zhou X., Wong L.L., Karakoti A.S., Seal S., McGinnis J.F. (2011).Nanoceria extend photoreceptor cell lifespan in tubby mice by modulation of apoptosis/survival signaling pathways. Neurobiology of Disease, 42, 514-23.

Kostova I. (2005). Synthetic and natural coumarins as cytotoxic agents. Current Medicinal Chemistry - Anticancer Agents 5:29-46.

Kozhemiakin MB., Draguhn A., Skrebitsky V.G. (2004). Layer-specific potentiation of evoked IPSCs in rat hippocampal CA1 pyramidal cells by lanthanum.Brain Research Bulletin 64: 97-101.

Krishnamurthy D., Weinberg V., Cunha J.A., Hsu I.C., Pouliot J. (2011).Comparison of high-dose rate prostate brachytherapy dose distributions with iridium-192, ytterbium-169, and thulium-170 sources.Brachytherapy 10: 461-65. doi: 10.1016/j.brachy.2011.01.012.

Kumamoto, E. \& Murata, Y. (1996). Lack of correlation between the molecular size and efficacy of lanthanides for potentiating GABAA currents in rat septal cholinergic neurons in culture. Brain. Research723, 235-237.

Kuryshev Y.A., Haak L., Childs G.V., Ritchie A.K. (1997). Corticotropin releasing hormone inhibits an inwardly rectifying potassium current in rat corticotropes.Journal of Physiology 502: 265-79.

Lansman J.B. (1990).Blockade of current through single calcium channels by trivalent lanthanide cations. Effect of ionic radius on the rates of ion entry and exit. The Journal of General Physiology 95: 679-96.

Leffler A., Linte R.M., Nau C., Reeh P., Babes A. (2007). A high-threshold heatactivated channel in cultured rat dorsal root ganglion neurons resembles TRPV2 and is blocked by gadolinium. European Journal of Neuroscience 26: 12-22. 
Lei S., MacDonald J.F. (2001). Gadolinium reduces AMPA receptor desensitization and deactivation in hippocampal neurons. Journal of Neurophysiology 86:173-82.

Liapi C., Zarros A., Theocharis S., Al-Humadi H., Anifantaki F., Gkrouzman E., Mellios Z., Skandali N., Tsakiris S. (2009). The neuroprotective role of L-cysteine towards the effects of short-term exposure to lanthanum on the adult rat brain antioxidant status and the activities of acetylcholinesterase, $(\mathrm{Na}+, \mathrm{K}+)$ - and $\mathrm{Mg} 2+-$ ATPase.Biometals. 22:329-35. doi: 10.1007/s10534-008-9169-0.

Liu H., Yang J., Liu Q., Jin C., Wu S., Lu X., Zheng L., Xi Q., Cai Y. (2014). Lanthanum chloride impairs spatial memory through ERK/MSK1 signaling pathway of hippocampus in rats.Neurochemical Research 39:2479-91. doi: 10.1007/s11064014-1452-6. 15.

Liu H., Yuan L., Yang X. and Wang K. (2003). $\mathrm{La}^{3+}, \mathrm{Gd}^{3+}$ and $\mathrm{Yb}^{3+}$ induced changes in mitochondrial structure, membrane permeability, cytochrome $c$ release and intracellular ROS level. Chemico-Biological Interactions 146, 27-37.

Lopatina L.P., Vasim T.V., Fedorovich S.V., Konev S.V. (2005).Lanthanides induce neurotransmitter release from vesicular pool in the rat synaptosomes. Biofizika. 50:1120-4.

Lovell M., Markesbery W. (2007). Oxidative DNA damage in mild cognitive impairment and late-stage Alzheimer's disease. Nucleic Acids Research, 35, pp. 7497-7504

Lyapustina T., Goldfine C., Rhyee S., Babu K.M., Griswold M.K. (2018). Evaluating the Patient with Reported Gadolinium-Associated Illness. Journal of Medical Toxicology 2018 Nov 29. doi: 10.1007/s13181-018-0689-x.

Ma, J., Narahashi, T. (1993). Enhancement of gamma-aminobutyric acid-activated chloridechannel currents by lanthanides in rat dorsal root ganglion neurons. Journal of Neuroscience 13, 4872-4879.

Ma, J., Reuveny, E., Narahashi, T. (1994). Terbium modulation of single gammaaminobutyric acid-activated chloride channels in rat dorsal root ganglion neurons. Journal of Neuroscience14, 3835-3841.

Maggio N., Vlachos A. (2014). Synaptic plasticity at the interface of health and disease: new insights on the role of endoplasmic reticulum intracellular calcium stores.Neuroscience281 135-146. doi: 10.1016/j.neuroscience.2014.09.041

Mäkelä R., Wisden W., Korpi E.R. (1999). Loreclezole and La3+ differentiate cerebellar granule cell $\mathrm{GABA}(\mathrm{A})$ receptor subtypes. European Journal Pharmacology367:101-15.

Markesbery, W. R., Lovell, M. A. (2007). Damage to lipids, proteins, DNA, and RNA in mild cognitive impairment. Archives of neurology, 64(7), 954-956. 
Mehta M.P., Shapiro W.R., Phan S.C., Gervais R., Carrie C., Chabot P., Patchell R.A., Glantz M.J., Recht L., Langer C., Sur R.K., Roa W.H., Mahe M.A., Fortin A., Nieder C., Meyers C.A., Smith J.A., Miller R.A., Renschler M.F. (2009). Motexafin gadolinium combined with prompt whole brain radiotherapy prolongs time to neurologic progression in non-small-cell lung cancer patients with brain metastases: results of a phase III trial. I International Journal of Radiation Oncology, Biology, Physics 73:1069-76. doi: 10.1016/j.jirobp.2008.05.068.

Miledi R. (1975). Lanthanum ions abolish the "calcium response" of nerve terminals.Nature229: 410-1.

Millward J.M., Ariza de Schellenberger A., Berndt D., Hanke-Vela L., Schellenberger E., Waiczies S., Taupitz M., Kobayashi Y., Wagner S., Infante-Duarte C. (2017). Application of Europium-Doped Very Small Iron Oxide Nanoparticles to Visualize Neuroinflammation with MRI and Fluorescence Microscopy.Neuroscience. 2017 Dec 19: 30886-2. doi: 10.1016/j.neuroscience

Mlinar, B., Enyeart, J. (1993). Block of current through T-type calcium channels by trivalentmetal cations and nickel in neural rat and human cells. Journal of Physiology (London) 469, 639-652.

Mueller-Tribbensee S.M., Karna M., Khalil M., Neurath M.F., Reeh P.W., Engel M.A. (2015). Differential Contribution of TRPA1, TRPV4 and TRPM8 to Colonic Nociception in Mice. PLoS One.10:e 0128242. doi:10.1371/journal.pone.0128242.

Nakamura, Y., Tsumura, Y., Shibata, T. , Ito, Y. (1997) Differences in behavior among the chlorides of seven rare earth elements administered intravenously to rats. Fundamental and AppliedToxicology37, 106-116.

Narahashi, T., Ma, J., Arakawa, O., Reuveny, Nakahiro, M. (1994). GABA receptorchannelcomplex as a target site of mercury, copper, zinc and lanthanides. Cellular and Molecular Neurobiology14, 599-621.

Ni J.Z. (2002). Bioinorganic chemistry of rare earth elements. Science, Beijing, pp 112.

Nikam S., Nikam P., Ahaley S., Sontakke A. (2009). Oxidative stress in Parkinson's disease. Indian Journal of Clinical Biochemistry, 24, pp. 98-101

Niu P.Y., Niu Q., Zhang Q.L., Wang L.P., He S.E., Wu T.C., Conti P., Di Gioacchino M., Boscolo P. (2005). Aluminum impairs rat neural cell mitochondria in vitro. International Journal of Immunopathology and Pharmacology. 18:683-89.

Oen I.M., van Baar M.E., Middelkoop E., Nieuwenhuis M.K.; Facial Burns Group (2012). Effectiveness of cerium nitrate-silver sulfadiazine in the treatment of facial burns: a multicenter, randomized, controlled trial.Plastic Reconstruction Surgery. 130:274e-283e. doi: 10.1097/PRS.0b013e3182589d63 
O'Sullivan N.C., Croydon L., McGettigan P.A., Pickering M., Murphy K.J. (2010). Hippocampal region-specific regulation of NF-kappaB may contribute to learningassociated synaptic reorganisation. Brain Research Bulletin 81:385-90. doi: 10.1016/j.brainresbull.2009.11.001.

Pałasz A., Czekaj P. (2000). Toxicological and cytophysiological aspects of lanthanides action. ActaBiochimicaPolonica 47: 1107-14.

Perazella M.A, Rodby R.A. (2007). Gadolinium use in patients with kidney disease: a cause for concern.Seminars in Dialysis. 20:179-85.

Przywara D.A., Bhave S.V., Bhave A., Chowdhury P.S., Wakade T.D., Wakade A.R. (1992). Activation of $K_{+}$channels by lanthanum contributes to the block of transmitter release in chick and rat sympathetic neurons. Journal of Membrane Biology 125: 155-62.

Ranjbar A., SoleimaniAsl S., Firozian F., HeidaryDartoti H., Seyedabadi S., Taheri Azandariani M., Ganji M. (2018) Role of Cerium Oxide Nanoparticles in a ParaquatInduced Model of Oxidative Stress: Emergence of Neuroprotective Results in the Brain. Journal of Molecular Neuroscence66:420-427

Riccio A., Mattei C., Kelsell R.E., Medhurst A.D., Calver A.R., Randall A.D., Davis J.B., Benham C.D., Pangalos M.N. (2002). Cloning and functional expression of human short TRP7, a candidate protein for store-operated $\mathrm{Ca2}+$ influx.Journal of Biological Chemistry277:12302-09..

Robbins T.W., Murphy E.R. (2006).Behavioural pharmacology: 40+ years of progress, with a focus on glutamate receptors and cognition. Trends in Pharmacological Sciences 27:141-148. doi: 10.1016/j.tips.2006.01.009

Rzigalinski B.A., Carfagna C.S., Ehrich M. (2017) Cerium oxide nanoparticles in neuroprotection and considerations for efficacy and safety. Wiley Interdisciplinary Reviews in Nanomedicine andNanobiotechnology. 9 (4).doi: 10.1002/wnan.1444.

Sárközi S., Komáromi I., Jóna I., Almássy J. (2017). Lanthanides Report Calcium Sensor in the Vestibule of Ryanodine Receptor. Biophysical Journal 112: 2127-2137. doi: 10.1016/j.bpj.2017.03.023.

Saxena N.C., Neelands T.R., MacDonald R.L. (1997). Contrasting actions of lanthanum on different recombinant gamma-aminobutyric acid receptor isoforms expressed in L929 fibroblasts. Molecular Pharmacology 51:328-35.

Schaefer M., Plant T.D., Stresow N., Albrecht N., Schultz G. (2002). Functional differences between TRPC4 splice variants.Journal of Biological Chemistry 277:3752-59.

Schubert D., Dargusch R., Raitano J., Chan SW. (2006) Cerium and yttrium oxide nanoparticles are neuroprotective. Biochemical and Biophysical Research Communications 342:86-91. 
Sharonova I.N., Dvorzhak A.Y., Vorobjov V.S. (2008). Gadolinium blocks protonactivated currents in isolated Purkinje cells.Bulletin of Experimental Biology and Medicine 145: 307-11.

Shukla V., Mishra, S. K., Pant, H. C. (2011). Oxidative stress in neurodegeneration. Advances in Pharmacological Sciences, 2011.2011:572634

Shuvaev S., Pal R., Parker D. (2017). Selectively switching on europium emission in drug site one of human serum albumin. Chemical Communications (Cambridge). 53: 6724-6727. doi: 10.1039/c7cc03071a

Smith S.M., Bergsman J.B., Harata N.C., Scheller R.H., Tsien R.W. (2004). Recordings from single neocortical nerve terminals reveal a nonselective cation channel activated by decreases in extracellular calcium. Neuron. 41:243-56

Sun Y., Yang J., Hu X., Gao X., Li Y., Yu M., Liu S., Lu Y., Wang J., Huang L., Lu X., Jin C., Wu S., Cai Y.(2018a).Conditioned medium from overly excitatory primary astrocytes induced by La3+ increases apoptosis in primary neurons via upregulating the expression of NMDA receptors. Metallomics. 10:1016-1028. doi: $10.1039 / \mathrm{c} 8 \mathrm{mt} 00056 \mathrm{e}$

Sun Y., Yang J., Hu X., Gao X., Li Y., Yu M., Liu S., Lu X., Jin C., Wu S., Cai Y. (2018b).Lanthanum chloride reduces lactate production in primary culture rat cortical astrocytes and suppresses primary co-culture rat cortical astrocyte-neuron lactate transport.Archieves of Toxicology 92:1407-1419. doi: 10.1007/s00204-017-2148-x.

Tisi A, Passacantando M, Lozzi L, Riccitelli S, Bisti S, Maccarone R. (2019). Retinal long term neuroprotection by Cerium Oxide nanoparticles after an acute damage induced by high intensity light exposure. Experimental Eye Research 182: 30-38. doi:10.1016/j.exer.2019.03.003.

Toimela T., Tähti H. (2004). Mitochondrial viability and apoptosis induced by aluminum, mercuric mercury and methylmercury in cell lines of neural origin. Archives of Toxicology 78:565-74.

Vaccari A., Saba P.L., Mocci I., Ruiu S. (1999). Lanthanides stimulate [3H]tyramine binding in the rat striatum. Neuroscience Letters $261: 49-52$.

Valcheva-Traykova, M., Saso, L., \&.Kostova, I. (2014). Involvement of lanthanides in the free radicals homeostasis. Current Topics in Medicinal Chemistry, 14(22), 25082519.

Velasco-Estevez M., Mampay M., Boutin H., Chaney A., Warn P., Sharp A., Burgess E., Moeendarbary E., Dev K.K., Sheridan G.K. (2018). Infection Augments Expression of Mechanosensing Piezo1 Channels in Amyloid Plaque-Reactive Astrocytes.Frontiers in Aging Neuroscience 22 :332. doi: 10.3389/fnagi.2018.00332. eCollection 2018

Vitse J., Tchero H., Meaume S., Dompmartin A., Malloizel-Delaunay J., Géri C., Faure C., Herlin C., Teot L. (2018). Silver Sulfadiazine and Cerium Nitrate in Ischemic Skin Necrosis of the Leg and Foot: Results of a Prospective Randomized 
Controlled Study. The International Journal of Lower Extremity Wounds 17:151-160. doi: $10.1177 / 1534734618795534$.

Vu H.N., Subuyuj G.A., Vijayakumar S., Good N.M., Martinez-Gomez N.C., Skovran E. (2016) Lanthanide-Dependent Regulation of Methanol Oxidation Systems in Methylobacteriumextorquens AM1 and Their Contribution to Methanol Growth. Journal of Bacteriology 198:1250-9. doi: 10.1128/JB.00937-15.

Wadkins, T., Benz, J. \& Briner, W. (1998). The effect of lanthanum administration during neural tube formation on the emergence of swimming behavior. Metal lons in Biology and Medicine5: 168-171.

Waseem T.V., Lapatsina L.P., Fedorovich S.V. (2008). Influence of integrin-blocking peptide on gadolinium- and hypertonic shrinking-induced neurotransmitter release in rat brain synaptosomes. Neurochemical Research 33:1316-24. doi: 10.1007/s11064007-9585-5.

Watkins C.S., Mathie A. (1994). Modulation of the gating of the transient outward potassium current of rat isolated cerebellar granule neurons by lanthanum.

PflugersArchieves. 428: 209-16

Wehrmann M., Billard P., Martin-Meriadec A., Zegeye A., Klebensberger J. (2017) Functional Role of Lanthanides in Enzymatic Activity and Transcriptional Regulation of Pyrroloquinoline Quinone-Dependent Alcohol Dehydrogenases in Pseudomonas putida KT2440.MBio. 8: e00570-17. doi: 10.1128/mBio.00570-17.

Wu J., Yang J., Liu Q., Wu S., Ma H., Cai Y. (2013).Lanthanum induced primary neuronal apoptosis through mitochondrial dysfunction modulated by $\mathrm{Ca}^{2+}$ and $\mathrm{Bcl}-2$ family.Biological Trace Element Research 152:125-34. doi: 10.1007/s12011-0139601-3.

Xia Q., Feng X., Huang H., Du L., Yang X., Wang K. (2011). Gadolinium-induced oxidative stress triggers endoplasmic reticulum stress in rat cortical neurons. Journal of Neurochemistry. 117:38-47. doi: 10.1111/j.1471-4159.2010.07162.x.

Xu T., Zhang M., Hu J., Li Z., Wu T., Bao J., Wu S., Lei L., He D. (2017) Behavioral deficits and neural damage of Caenorhabditis elegans induced by three rare earth elements.Chemosphere 181:55-62. doi: 10.1016/j.chemosphere

Yang J., Liu Q., Wu S., Xi Q., Cai Y. (2013). Effects of lanthanum chloride on glutamate level, intracellular calcium concentration and caspases expression in the rat hippocampus.Biometals. 26:43-59. doi: 10.1007/s10534-012-9593-z.

Zha, H., Cheng, Z., Chen, J., Hu, R., Che, Y., Cui, Y., \& Hong, F. (2011). The toxicological effects in brain of mice following exposure to cerium chloride. Biological Trace Element Research, 144(1-3), 872-884.

Zhang J., Li Y., Hao X., Zhang Q., Yang K., Li L., Ma L., Wang S., Li X. (2011).Recent progress in therapeutic and diagnostic applications of lanthanides.Mini Reviews in Medicinal Chemistry 11: 678-94. 
Zhang L., Yang J., Wu S., Jin C., Lu X., Hu X., Sun Y., Gao X., Cai Y. (2017), Activation of Nrf2/ARE signaling pathway attenuates lanthanum chloride induced injuries in primary rat astrocytes.Metallomics. 9:1120-1131. doi: 10.1039/c7mt00182g.

Zhao, H., Cheng, Z., Hu, R., Chen, J., Hong, M., Zhou, M., ... \& Hong, F. (2011). Oxidative injury in the brain of mice caused by lanthanid. Biological Trace Element Research, 142(2), 174-189.

Zheng L., Yang J., Liu Q., Yu F., Wu S., Jin C., Lu X., Zhang L., Du Y., Xi Q., Cai Y. (2013). Lanthanum chloride impairs spatial learning and memory and downregulates NF-KB signalling pathway in rats. Archieves of Toxicology 87:2105-17. doi: 10.1007/s00204-013-1076-7.

Zhou C., Huang Y., Przedborski S. (2008). Oxidative stress in Parkinson's disease: A mechanism of pathogenic and therapeutic significance. Annals of New York Academy of Sciences, 1147, pp. 104.

Figure captions

Fig.1. An outline of chemical characteristics of the lanthanides, scandium and yttrium.

Fig.2.A collective scheme of the main effects of lanthanides on synaptic transmission and neuronal physiology. An expression of several neuronal receptors, membrane transporters, regulatory proteins and their genes as well as activity of some enzymes can be modulated by lanthanide ions. Lanthanum, the best surveyed member of the rare-earths family may facilitate the neurotransmitter release via activation of synaptobrevin-2 molecule Lanthanum may also stimulate the GABAA receptor to open chloride channel and cause postsynaptic hyperpolarization. Additionally it is able to affect the voltage-gated potassium and sodium channels (VGSC, VGKC), AChE activity and to trigger the neural apoptosis through the stimulation of Bax and inhibition of Bcl-2 expressions. Cerium increases the expression of apoptosis-related genes e.g. antagonizing transcription factor (TRB), ubiquitin-conjugating enzyme e2 (UBE2V1), cysteine-serine-rich nuclear protein1 (AXUD1) and cell division 37 homolog (CDC37); while suppressing several genes involved in the neurochemistry of memory and learning e.g. Fos, Adcy8 and Slc5a7.Abbreviations: AChE;acetylocholinoesterase, $\quad$ AMPA; a-amino-3-hydroxy-5-methyl-4isoxazolepropionic acid glutamate receptor, Axud1; cysteine-serine-rich nuclear protein1, Adcy8;calcium-stimulated adenylyl cyclase, Cdd37; cell division 37 homologue, Fos; proto-oncogene AP-1 transcription factor subunit, G; protein $\mathrm{G}$, 
GLAST;glutamateaspartate transporter GS; glutamine syntethase, KAR; kainate glutamatergic receptor, mGluR; metabotropic glutamate receptor, NERT; norepinephrine transporter, NMDA; N-methyl-D-aspartate glutamatergic receptor, PAG; phosphate activated glutaminase, SIc5a7; solute carrier family 5 member 7 gene, SNARE; soluble NSF attachment protein, TRPVs; vanilloid-type heat-activated ion channels,Ube2v1; ubiquitin-conjugating enzyme e2, VGKC; voltage gated potassium channel, VGSC; voltage gated sodium channels.

Fig.3. Mechanism of lanthanides-induced oxidative injury in neurons and astrocytes. Lanthanum promotes both ROS production and lipid peroxidation in neurons and astrocytes and decreases activities of key endogenous antioxidant enzymes: superoxide dismutase (SOD), catalase, ascorbic acid and glutathione peroxidases (APx, GSH-Px). Gadolinium with a minimal redox activity does not bind to thiol groups but affects the endoplasmic reticulum IRE1-XBP1, PERK and ATF6 pathways, increasing GRP78 expression that finally trigger unfolded protein response (UPR) signaling pathways via the CCAAT/enhancer binding protein homologous protein (CHOP or Gadd153) activation apoptosis is triggered. Abbreviations: CHOP; CCAAT/enhancer binding protein homologous protein, GST; glutathione-S-transferase, $\quad \gamma$-GCS; $\gamma$-glutamine cysteine synthase, HO-1; hemeoxygenase1, NAC; $\mathrm{N}$-acetylcysteine, NQO1; dehydrogenase quinone 1, Nrf2/ARE;nuclear factor erythroid-derived 2-like 2 antioxidant response, TBHQ;tertbuthyl-hydroquinone, UPR; unfolded protein responses.

Fig.4. Neuroprotective effects of lanthanide compounds. 


\begin{tabular}{|c|c|c|c|c|c|}
\hline Element & Ion forms & $\begin{array}{l}\text { Ionic radii } \\
\text { (pm) }\end{array}$ & $\begin{array}{c}\text { Electronegativity } \\
\text { (Pauling scale) }\end{array}$ & $\begin{array}{c}\text { Electron } \\
\text { configuration }\end{array}$ & Discovery \\
\hline Lanthanum & $\mathrm{La}^{3+}$ & 122 & 1.10 & {$[\mathrm{Xe}] 5 d^{1} 6 s^{2}$} & C. G. Mosander, 1839, Stockholm \\
\hline Cerium & $\mathrm{Ce}^{3+} \mathrm{Ce}^{4+}$ & 107,94 & 1.12 & {$[X e] 4 f^{2} 6 s^{2}$} & J. J. Berzelius, W. Hisinger, 1803 , Sweden \\
\hline Praseodymium & $\mathrm{Pr}^{3+}$ & 106 & 1.13 & {$[X e] 4 f^{3} 6 s^{2}$} & K. Auer von Welsbach, 1885 , Vienna \\
\hline Neodymium & $\mathrm{Nd}^{3+}$ & 104 & 1.14 & {$[X e] 4 f^{4} 6 s^{2}$} & K. Auer von Welsbach, 1885, Vienna \\
\hline Promethium* & $\mathrm{Pm}^{3+}$ & 106 & 1.13 & {$[X e] 4 f^{5} 6 s^{2}$} & J. A. Marinsky, L.E. Glendenin, C.D Coryell, 1945, USA \\
\hline Samarium & $\mathrm{Sm}^{2+} \mathrm{Sm}^{3+}$ & 111,100 & 1.17 & {$[X e] 4 f^{6} 6 s^{2}$} & P. E. Lecoq de Boisbaudran, 1879, Paris \\
\hline Europium & $\mathrm{Eu}^{2+} \mathrm{Eu}^{3+}$ & 112,98 & 1.20 & {$[X e] 4 f^{7} 6 s^{2}$} & E. A. Demarçay, 1901, Paris \\
\hline Gadolinium & $\mathrm{Gd}^{3+}$ & 97 & 1.20 & {$[X e] 4 f^{7} 5 d^{1} 6 s^{2}$} & J. C. Galissard de Marignac, 1880, Geneva \\
\hline Terbium & $\mathrm{Tb}^{3+} \mathrm{Tb}^{4+}$ & 93,81 & 1.22 & {$[X e] 4 f^{9} 6 s^{2}$} & C. G. Mosander, 1843, Stockholm \\
\hline Dysprosium & $\mathrm{Dy}^{3+}$ & 91 & 1.22 & {$[\mathrm{Xe}] 4 \mathrm{f}^{10} 6 \mathrm{~s}^{2}$} & P. E. Lecoq de Boisbaudran, 1886, Paris \\
\hline Holmium & $\mathrm{Ho}^{3+}$ & 89 & 1.23 & {$[X e] 4 f^{11} 6 s^{2}$} & P. T. Cleve, 1878, Uppsala (Sweden) \\
\hline Erbium & $\mathrm{Er}^{3+}$ & 89 & 1.24 & {$[\mathrm{Xe}] 4 \mathrm{f}^{12} 6 \mathrm{~s}^{2}$} & C.G. Mosander, 1842, Stockholm \\
\hline Thulium & $\mathrm{Tm}^{3+} \mathrm{Tm}^{4+}$ & 104,94 & 1.25 & {$[\mathrm{Xe}] 4 \mathrm{f}^{13} 6 \mathrm{~s}^{2}$} & P. E. Lecoq de Boisbaudran, 1886, Paris \\
\hline Ytterbium & $\mathrm{Yb}^{2+} \mathrm{Yb}^{3+}$ & 113,86 & 1.22 & {$[\mathrm{Xe}] 4 \mathrm{f}^{14} 6 \mathrm{~s}^{2}$} & J. C. Galissard de Marignac, 1878, Geneva \\
\hline Lutetium & $\mathrm{Lu}^{3+}$ & 85 & 1.27 & {$[X e] 4 f^{14} 5 d^{1} 6 s^{2}$} & G. Urbain, 1907, Paris \\
\hline Scandium & $\mathrm{Sc}^{3+}$ & 83 & 1.36 & {$[A r] 3 d^{1} 4 s^{2}$} & L. F. Nilson, 1879, Uppsala (Sweden) \\
\hline Yttrium & $Y^{3+}$ & 106 & 1.22 & {$[K r] 4 d^{1} 5 s^{2}$} & J. Gadolin, 1794, Ábo (Finland) \\
\hline
\end{tabular}

*radioactive, artificially obtained element, not found in nature on Earth

This article is protected by copyright. All rights reserved. 


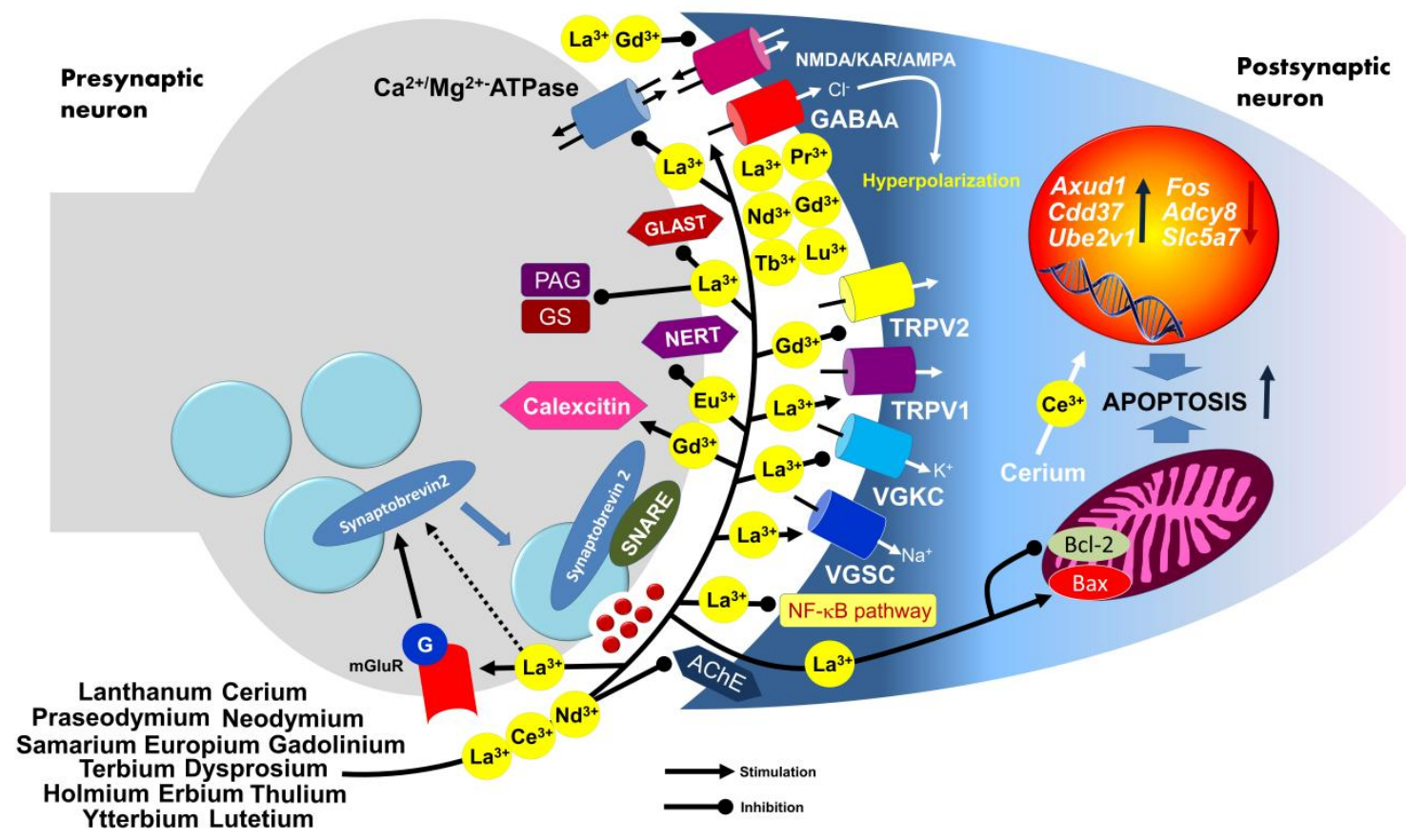

This article is protected by copyright. All rights reserved. 


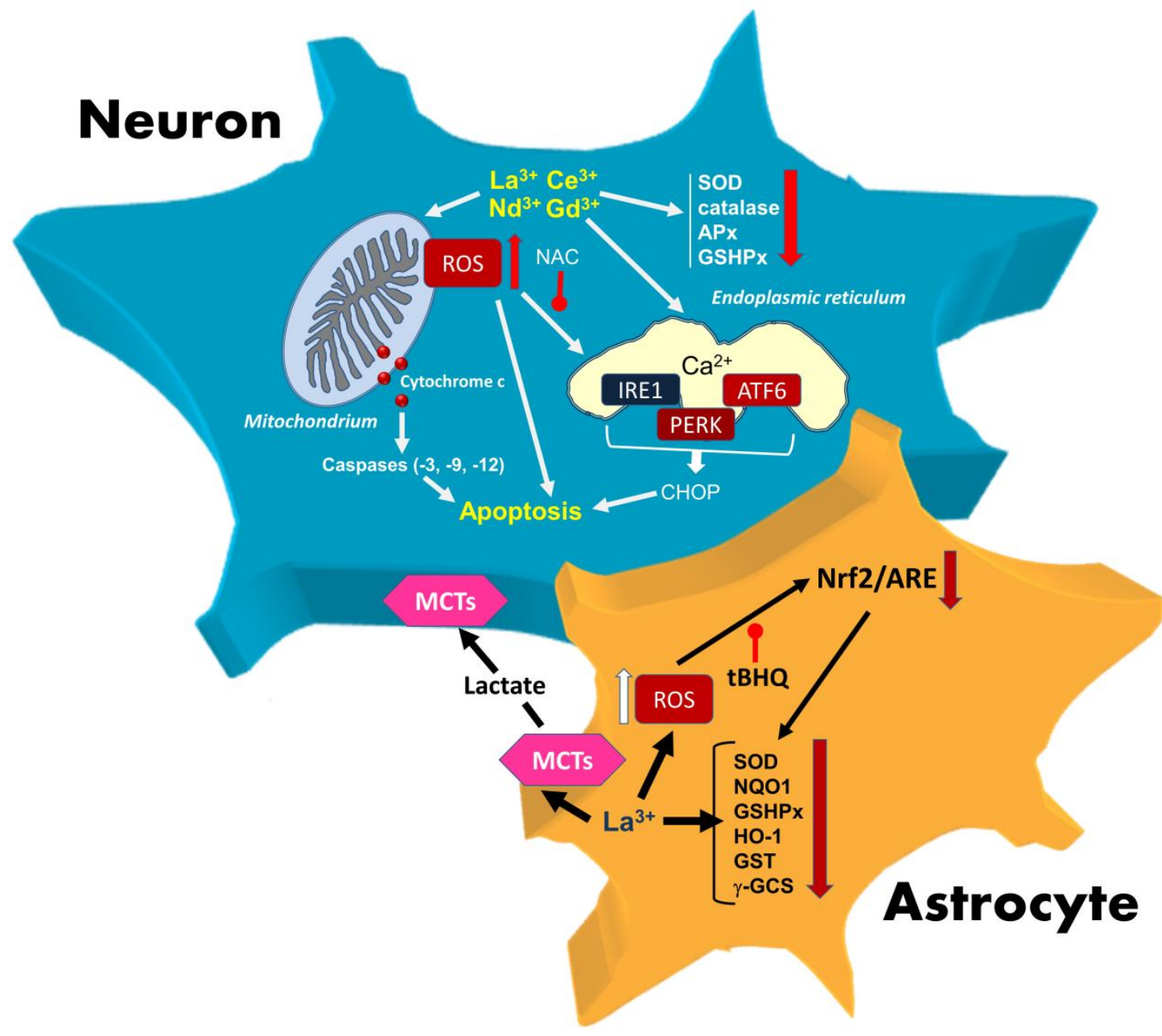

This article is protected by copyright. All rights reserved. 


\begin{tabular}{|c|c|c|}
\hline Lanthanide compound & Neuroprotective effects & References \\
\hline \multirow{8}{*}{$\begin{array}{c}\text { Nanoceria } \\
\text { Cerium oxide }\left(\mathrm{CeO}_{2}\right)\end{array}$} & $\begin{array}{l}\text { decrease of interleukin IL-17, IL-10, and IL- } 6 \text { gene expressions and their } \\
\text { serum levels in the brain inflammation model }\end{array}$ & Hekmatimoghaddam et al. 2019 \\
\hline & $\begin{array}{l}\text { amelioration of the oxidative DNA damage and caspase- } 3 \text { level, } \\
\text { increasing total antioxidant capacity and total thiol molecules, } \\
\text { enhancing nestin and Neurod1 mRNA expression levels in the rat brain }\end{array}$ & Rajnbar et al. 2018 \\
\hline & $\begin{array}{l}\text { reduction of reactive oxygen species levels, alleviation of clinical } \\
\text { symptoms and motor impairment in mice with an animal model of MS }\end{array}$ & Heckman et al. 2013 \\
\hline & $\begin{array}{l}\text { decrease of macromolecular free radical neuronal injury, improvement } \\
\text { of cognitive function after in vivo mild traumatic brain damage }\end{array}$ & Bailey et al. 2016 \\
\hline & $\begin{array}{l}\text { reduction in reactive oxygen species, decrease of the ischemia-induced } \\
\text { 3-nitrotyrosine levels, a modification to tyrosine residues in proteins } \\
\text { affected by the peroxynitrite radical in the mouse hippocampal slices in } \\
\text { animal model of cerebral ischemia }\end{array}$ & Estevez et al. 2011 \\
\hline & $\begin{array}{l}\text { decrease of reactive nitrogen species levels and protein tyrosine } \\
\text { nitration in neurons exposed to peroxynitrite, reduction of peroxynitrite } \\
\text { and } A \beta \text {-induced mitochondrial fragmentation }\end{array}$ & Dowding et al. 2014 \\
\hline & $\begin{array}{l}\text { reduction of microglial activation and their migration toward outer } \\
\text { nuclear layer in the rat light-damaged retina photoreceptor cells }\end{array}$ & Fiorani et al. 2015 \\
\hline & $\begin{array}{l}\text { a potent anti-reactive oxygen species activity, improvement of both cell } \\
\text { differentiation and dopamine production in cultured neuron-like PC12 } \\
\text { cells }\end{array}$ & Ciofani et al. 2013 \\
\hline Yttrium oxide $\left(\mathrm{Y}_{2} \mathrm{O}_{3}\right)$ & $\begin{array}{l}\text { limitation of the amount of reactive oxygen species required to kill the } \\
\text { cells }\end{array}$ & Schubert et al. 2006 \\
\hline $\begin{array}{l}\text { Gadolinium chloride } \\
\qquad\left(\mathrm{GdCl}_{3}\right)\end{array}$ & $\begin{array}{l}\text { significant attenuation of ischemic reperfusion-induced infarct size, } \\
\text { behavioral and biochemical changes in mice brain }\end{array}$ & Gulati et al. 2013 \\
\hline
\end{tabular}

This article is protected by copyright. All rights reserved. 